\title{
PARTICIPAÇÃO DA CONTROLADORIA NO PROCESSO DE GESTÃO DAS ORGANIZAÇÕES: UMA ANÁLISE COMPARATIVA ENTRE GRANDES INDÚSTRIAS DE SANTA CATARINA E DO RIO GRANDE DO SUL
}

\author{
Édina Elisangela Zellmer Fietz ${ }^{1}$ \\ Adilson Costa ${ }^{2}$ \\ Ilse Maria Beuren ${ }^{3}$
}

\begin{abstract}
Resumo: Conhecer o papel do Controller e suas atribuições é o primeiro passo para implantação do departamento de Controladoria em uma empresa, mas também é importante a conscientização dos gestores para uma atividade conjunta a fim de viabilizar o empreendimento. Este artigo traça um comparativo entre a participação da Controladoria no processo de gestão de grandes indústrias de Santa Catarina e do Rio Grande do Sul. Para o embasamento desse comparativo, reaplicou-se o questionário aplicado em grandes indústrias do Rio Grande do Sul por Giongo (2005), em 20 indústrias têxteis do Vale do Itajaí, em Santa Catarina. Os resultados da pesquisa evidenciaram a atuação da Controladoria em empresas de Estados distintos, focalizando diferentes formas de gestão; levantaram informações sobre o surgimento da Controladoria nessas indústrias e sobre as pessoas responsáveis pelo seu controle. $\mathrm{Na}$ análise efetuada, os dois Estados pesquisados apresentaram fatores semelhantes e divergentes no que tange à participação da Controladoria no processo de gestão empresarial.
\end{abstract}

Palavras-chave: Controladoria. Processo de gestão empresarial. Empresas gaúchas e catarinenses.

\section{INTRODUÇÃO}

Devido à velocidade com que as mudanças vêm ocorrendo no mercado, a Controladoria está conquistando um espaço cada vez maior nas empresas. Com essas mudanças, o administrador, freqüentemente, precisa tomar rápidas decisões, o que requer informações corretas, precisas e de fácil acesso.

A Controladoria tem a missão de otimizar os resultados econômicos através da definição de um modelo de informações capaz de oferecer condições para o desenvolvimento da empresa. Para Mosimann; Fisch (1999, p. 108), "cabe à Controladoria, como um órgão da estrutura empresarial, administrar o sistema de informações econômico-financeiro da empresa e coordenar os esforços dos gestores de cada área no intuito de maximizar os resultados globais da empresa".

Atualmente, as empresas devem voltar mais suas atenções à otimização de resultados. Não existe mais a especulação financeira em grandes proporções, os ganhos deverão ser totalmente operacionais, advindos da exploração do negócio. Esse assunto se relaciona com a concepção da

\footnotetext{
1 Mestranda do Programa de Pós-Graduação em Ciências Contábeis, FURB, Blumenau, SC.

E-mail: financeiroctm @ senai-sc.ind.br.

2 Mestrando do Prog. de Pós-Graduação em Ciências Contábeis, FURB, Blumenau, SC.

E-mail: adilson.nominal@terra.com.br

3 Programa de Pós-Graduação em Ciências Contábeis, FURB, Blumenau, SC. E-mail: ilse@ @urb.br
} 
organização, na qual o principal objetivo da Controladoria é o de promover a eficácia operacional no intuito de viabilizar a gestão econômica.

O objetivo desse artigo é apresentar um comparativo entre a participação da Controladoria no processo de gestão de grandes indústrias de Santa Catarina e do Rio Grande do Sul. Para coleta de dados, reaplicou-se o questionário aplicado em grandes indústrias do Rio Grande do Sul por Giongo (2005), em 20 indústrias têxteis do Vale do Itajaí, em Santa Catarina.

Este trabalho é composto por introdução, revisão de literatura, metodologia da pesquisa, análise dos dados da pesquisa realizada em Santa Catarina e a comparação dos resultados com os obtidos na pesquisa feita no Rio Grande do Sul e, por fim, as conclusões.

\title{
2 FUNDAMENTOS E FUNÇÕES DA CONTROLADORIA
}

No início do século XX, a Controladoria surgiu devido à necessidade das empresas controlarem sua cadeia de valores através de estratégias e do planejamento de suas atividades, tornando as informações cada vez mais importantes para a tomada de decisão. Para Kanitz (1976, p. 5), "a Controladoria originou-se de pessoas que exerciam cargos de responsabilidade no departamento contábil, ou no departamento financeiro, uma vez que esses profissionais possuem uma visão ampla da empresa, capacidade esta que os tornou capazes de detectar as dificuldades e propor soluções".

Inicialmente os profissionais contábeis e financeiros exerciam, dentro das organizações, o trabalho de verificação das movimentações para que estivessem de acordo com 0 processo, interferindo a ponto de detectar desvios que por ventura viessem a ocorrer. A partir desse procedimento é que se originou a Controladoria, ou seja, profissionais controladores da execução dos processos dentro da empresa. A respeito do surgimento da Controladoria, Beuren (2002, p. 20) afirma que:

\begin{abstract}
a Controladoria surgiu [...] com a finalidade de realizar rígido controle de todos os negócios das empresas relacionadas, subsidiárias e/ou filiais. 0 crescimento vertical e diversificado desses conglomerados exigia, por parte dos acionistas e gestores, um controle na central em relação aos departamentos e divisões. Todo este desenvolvimento deu-se em virtude de três fatores: verticalização, diversificação e expansão geográfica das organizações, e 0 conseqüente aumento da complexidade das suas atividades o que exigiu outro tipo de controle por parte da Controladoria, contribuindo para a ampliação das funções do controller.
\end{abstract}

Também segundo Beuren (2002, p. 21), "o verdadeiro significado do termo Controladoria ainda não está totalmente definido na literatura". Ao longo dos tempos, diversos autores vêm tentando conceituar a palavra Controladoria. Oliveira (1998, p. 19) entende Controladoria como "o departamento responsável pelo projeto, elaboração, implementação e manutenção do sistema integrado de informações operacionais, financeiras e contábeis de uma determinada entidade, com ou sem finalidades lucrativas".

Para Oliveira (1998), a Controladoria deve ser capaz de organizar e reportar dados e informações relevantes, bem como exercer uma força capaz de influenciar às decisões dos administradores da entidade, pois é responsável pela manutenção e implementação de sistemas integrados de informações operacionais confiáveis.

Mossimann; Fisch (1999, p. 99) conceituam Controladoria como "um conjunto de princípios, procedimentos e métodos oriundos das ciências de Administração, Economia, Psicologia, Estatística e, principalmente, da Contabilidade, que se ocupa da gestão econômica das empresas, com a finalidade de orientá-las para a eficácia". Diante desse contexto, os autores concebem a Controladoria como uma 
área de conhecimento em que qualquer ciência lança mão de suas leis sem perder o conhecimento no seu campo de experimentação.

Peleias (2002, p.13) define a Controladoria como "uma área da organização à qual é delegada autoridade para tomar decisões sobre eventos, transações e atividades que possibilitem o adequado suporte ao processo de gestão". O autor também cita algumas formas de decisão em relação à organização, dentre elas, "critérios de identificar, prever, registrar e explicar eventos, transações e atividades", buscando assegurar eficácia nas diversas áreas organizacionais da empresa.

A partir desses conceitos, alguns aspectos em relação à Controladoria são identificados, um deles baseia-se na missão, ou função, em que a Controladoria busca obter informações das pessoas e das áreas de conhecimento. Após pesquisas e análises desses dados, define a própria meta, comunicando-a sob a forma de intenções e efeitos de ordem financeira.

Riccio; Petters (1993, p. 9) afirmam que "a missão da Controladoria pode ser vista como a coordenação de esforços para que seja alcançada a sinergia que irá corresponder a um resultado global ou superior à soma dos resultados individuais das áreas, garantindo o cumprimento da missão e da continuidade da organização".

Figueiredo; Cagiano (2004, p. 26) entendem que "a missão da Controladoria é zelar pela continuidade da empresa, assegurando a otimização do resultado global". Nesse sentido, Peleias (2002, p.16) acrescenta que a missão da Controladoria é "[...] assegurar a otimização do resultado econômico da organização".

Mosimann; Fisch (1999, p. 90), por sua vez, entendem que a missão da Controladoria consiste em "otimizar os resultados econômicos da empresa, objetivando garantir sua continuidade, através da integração de esforços das suas diversas áreas".

Sendo assim, a missão da Controladoria pode ser entendida como a integração de esforços individuais das áreas de uma entidade para otimizar o seu resultado econômico, garantindo 0 cumprimento da missão e da continuidade da organização.

Quanto às funções da Controladoria, Almeida; Parisi; Pereira (2001) afirmam que são: a) subsidiar o processo de gestão; b) apoiar a avaliação de desempenho; c) apoiar a avaliação de resultado; d) gerir os sistemas de informações; e) atender aos agentes do mercado.

No subsídio ao processo de gestão, Almeida; Parisi; Pereira (2001) consideram que a Controladoria deve dar suporte para que a entidade ajuste seu processo gestão ao meio em que está inserida. No apoio à avaliação de desempenho, a Controladoria assume o papel de analisar 0 desempenho econômico das diversas áreas, dos gestores e da empresa como um todo. Quanto ao apoio na avaliação dos resultados dos produtos e serviços, tem como função monitorar e orientar 0 processo de estabelecimento de padrões, bem como avaliar os resultados dos seus serviços. Ao gerir sistemas de informação, cabe a Controladoria definir a base de dados que organizará as informações necessárias. É função do setor atender aos agentes do mercado a partir da análise e mensuração do impacto das legislações no resultado econômico da empresa.

Sobre a função da Controladoria, Kanitz $(1976$, p. 6) referiu-se alertando que:

não está restrita à administração do sistema contábil da empresa, pois o controller recebe ajuda de administradores organizacionais, psicólogos industriais, analistas de sistemas, especialistas em computação, estatísticos e matemáticos, que têm a tarefa de analisar e dirigir, de acordo com a sua área do conhecimento, as informações necessárias ao cumprimento da função de Controladoria.

Perez Júnior; Oliveira; Costa (1999, p. 280) entendem que "a Controladoria deve direcionar suas atividades e funções no sentido de atuar como consultoria de alto nível, ou seja, deve estar voltada para a gestão da empresa e para a eficaz contribuição ao planejamento, controle e discussão 
das políticas estratégicas". A afirmação dos autores de que o setor deve ter seu posicionamento tradicional alterado para o centro de lucros, fundamenta-se na idéia de que a Controladoria é um setor indispensável para uma entidade, capaz de auxiliar, assessorar a gestão, agregando esforços para otimizar o resultado econômico.

Anthony e Govindarajan (2002, p.156) explicam que a função da Controladoria é:

de assessoria, no organograma. Embora o controller seja usualmente responsável pelo projeto e pela operação de sistemas que coletam, relatam e controlam informações, o uso destas, no controle, é de responsabilidade dos executivos de linha. 0 controller pode também ser responsável pelo desenvolvimento e pela análise de avaliações dos controles, e por recomendações aos executivos. Além disso, pode controlar o respeito aos limites de gastos instituídos pelo executivo-chefe, controlar a integridade do sistema contábil e ser responsável pelas medidas de segurança dos ativos contra furtos e fraudes.

Dessa forma, a Controladoria passa a ser de fundamental importância no sentido de propiciar aos gestores informações para a tomada de decisão e para o acompanhamento da real situação da empresa. A correta definição dos objetivos da empresa e a correlação destes com uma estratégia compatível consistem em instrumentos e informações necessárias para a execução das funções da Controladoria, sendo necessário adequar a gestão da entidade aos dados obtidos na Controladoria, visando garantir sua continuidade.

De acordo com Mosimann; Fisch (1999, p. 115), "não faz sentido planejar se o que foi planejado não se constituir em uma diretriz para a execução". Sendo assim, a Controladoria auxilia a gestão de uma entidade a partir da função de "apoio na avaliação de resultados". Especialmente quando monitora e orienta o processo de estabelecimento de padrões, bem como avalia os resultados, preocupando-se em controlar os desvios do realizado em relação ao planejado, as causas desses desvios e a necessidade de tomada de ações corretivas.

Diversas são as contribuições da Controladoria no processo de gestão. Peleias (2002) cita-as como sendo: a) subsídio à etapa de planejamento; b) subsídio à etapa de execução; c) subsídio à etapa de controle; d) elaboração da análise de desempenho; e) definição das regras de realização da análise dos resultados, participação, monitoramento e orientação do processo de estabelecimento de padrões e avaliação do resultado dos serviços prestados à entidade.

No que diz respeito ao planejamento, Peleias (2002) afirma que a Controladoria contribui com os gestores na avaliação do impacto de diversas alternativas, disponibilizando informações e instrumentos, além de atuar como um agente que une esforços para coordenação do planejamento operacional. Na etapa de execução, a contribuição do setor é através do fornecimento de informações que permitem comparar com o padrão, os desempenhos realizados pela entidade. $\mathrm{Na}$ etapa de controle, a contribuição acontece através do subsídio de informações para a comparação da atuação dos gestores e das áreas de responsabilidade como, por exemplo, o obtido com os produtos e serviços de acordo com os padrões pré-estabelecidos.

Outra contribuição da Controladoria dá-se na elaboração da análise do desempenho para contribuição no cumprimento da missão da entidade: dos gestores, das áreas, bem como da atuação do próprio setor de Controladoria. Por fim, Peleias (2002) cita como contribuição: a definição das regras de realização da análise dos resultados gerados pelos produtos e serviços; a participação, monitoramento e orientação do processo de estabelecimento de padrões e a avaliação do resultado dos serviços que o setor presta à entidade.

De forma geral, o papel da Controladoria, segundo Perez Júnior; Pestana; Franco (1997), é assessorar a gestão da empresa, fornecendo avaliações de alternativas econômicas, integrando informações e apresentando-as para facilitar a tomada de decisão. Almeida; Parisi; Pereira (2001, p.348) afirmam que é "responsabilidade da Controladoria ser a indutora dos gestores no que diz 
respeito à melhoria das decisões, pois sua atuação envolve implementar um conjunto de ações cujos produtos materializam-se em instrumentos disponibilizados aos gestores".

Portanto, a Controladoria tem a função de dar suporte, além da elaboração do planejamento da organização, para a execução da missão da entidade, através da convergência de esforços das áreas e gestores, gerando informações relevantes para a tomada de decisões em todas as etapas do processo de gestão.

\title{
3 MÉTODO E PROCEDIMENTOS DA PESQUISA
}

A pesquisa realizada caracteriza-se como descritiva relacional. Segundo Martins (2002, p. 36), esta "tem como objetivo a descrição das características de determinada população ou fenômeno, bem como o estabelecimento de relações entre variáveis e fatos". Para Raupp; Beuren (2004, p. 81), a pesquisa descritiva "configura-se como um estudo intermediário entre pesquisa exploratória e a explicativa, ou seja, não é tão preliminar como a primeira nem tão profunda como a segunda".

$O$ procedimento utilizado para obtenção dos dados foi o de levantamento. Esse método de coleta é conceituado por Martins (2002, p. 36) como sendo o levantamento feito junto "às fontes primárias, geralmente através de aplicação de questionários para grande quantidade de pessoas". Para Gil (1999, p. 70) as pesquisas de levantamento caracterizam-se:

\begin{abstract}
pela interrogação direta das pessoas cujo comportamento se deseja conhecer. Basicamente, procede-se a solicitação de informações a um grupo significativo de pessoas acerca do problema estudado para em seguida, mediante análise quantitativa, obter as conclusões correspondentes aos dados coletados.
\end{abstract}

O instrumento para a coleta de dados consistiu-se em um questionário com perguntas fechadas. Para Gil (1999, p. 128), questionário é "a técnica de investigação composta por um número mais ou menos elevado de questões apresentadas por escrito às pessoas, tendo como objetivo 0 conhecimento de opiniões, crenças, sentimentos, interesses, expectativas, situações vivenciadas etc." Colauto; Beuren (2004, p. 131) advertem que "as perguntas devem ser claras, concretas e precisas, ter linguagem acessível ao entendimento da média da população estudada, possibilitar uma única interpretação, não sugerir ou induzir respostas."

Neste estudo, foi reaplicado o questionário utilizado na dissertação de Giongo (2005). 0 objetivo foi comparar os resultados da pesquisa realizada por ele em 48 indústrias de grande porte do Rio Grande do Sul - cadastradas junto à Federação das Indústrias do Estado do Rio Grande do Sul (FIERGS) - com os resultados obtidos na pesquisa realizada em 18 grandes indústrias têxteis de Santa Catarina, situadas no Vale do Itajaí. Para identificação das empresas no Estado de Santa Catarina, foi utilizada a relação das empresas listadas na dissertação de Andreatta (2005), cujo objetivo era verificar "a Controladoria nas grandes indústrias têxteis do Vale o Itajaí/SC". Do universo utilizado na dissertação de Andreatta (2005), ampliou-se em mais duas empresas, chegando-se a um total de 20.

Primeiro, entrou-se em contato com os responsáveis pela Controladoria para confirmar se 0 número do telefone e o endereço das empresas selecionadas não se haviam alterado. Em seguida enviou-se, por meio eletrônico, a carta de apresentação e o questionário para que os mesmos respondessem. Diversos contatos foram necessários até que todos respondessem o questionário. Das 20 empresas selecionadas, todas responderam, sendo que 19 devolveram por meio eletrônico e uma via fax. Uma das empresas respondeu que, por ser uma empresa pequena e de administração familiar, todas as decisões eram centralizadas naquela administração. 
Para análise dos dados foram utilizadas as abordagens qualitativa e quantitativa. Na primeira parte do estudo, foi utilizada metodologia de pesquisa qualitativa. Richardson (1980, p. 80) afirma que "os estudos que empregam uma metodologia qualitativa podem descrever a complexidade de determinado problema, analisar a interação de certas variáveis, compreender e classificar processos dinâmicos vividos por grupos sociais".

$\mathrm{Na}$ segunda parte deste artigo, utilizou-se a metodologia de pesquisa quantitativa. Segundo Raupp; Beuren (2004, p. 92), esta "caracteriza-se pelo emprego de instrumentos estatísticos, tanto na coleta quanto no tratamento dos dados". Toda pesquisa quantitativa baseia-se nos instrumentos estatísticos para transformar as respostas obtidas. Portanto, o propósito da pesquisa quantitativa é de medir os resultados de forma objetiva.

Richardson (1980, p. 70) afirma que a abordagem quantitativa caracteriza-se pelo emprego de "quantificação tanto nas modalidades de coleta de informações, quanto no tratamento delas por meio de técnicas estatísticas, desde as mais simples, como percentual, média, desvio-padrão, às mais complexas, como coeficiente de correlação, análise de regressão etc."

No que se refere às limitações da pesquisa, destaca-se a reaplicação do questionário adotado na dissertação de Giongo (2005), assim como a utilização da mesma como fonte secundária de dados. Vale salientar, entretanto, que tais limitações foram consideradas anteriormente para não comprometer 0 alcance do objetivo a que se propõe o presente estudo.

\section{APRESENTAÇÃO DOS DADOS DA PESQUISA REALIZADA NO ESTADO DO RIO GRANDE DO SUL}

Para comparar os dados desta pesquisa foi utilizada como referência a pesquisa intitulada "A participação da Controladoria no processo de gestão das organizações", de autoria de Juliano Giongo (2005). O quadro 1 apresenta um resumo das constatações de Giongo (2005) na pesquisa realizada junto às empresas industriais de grande porte do Estado do Rio Grande do Sul, cadastradas junto à FIERGS.

\begin{tabular}{|l|l|}
\hline \multicolumn{1}{|c|}{ DADOS } & \multicolumn{1}{c|}{ ANÁLISE } \\
\hline 1) Análise do perfil das empresas e dos respondentes da pesquisa \\
\hline $\begin{array}{l}73 \% \text { das empresas possuem área formalizada } \\
\text { de Controladoria. }\end{array}$ & $\begin{array}{l}\text { Percentual satisfatório, porém, por se tratar de } \\
\text { empresas industriais de grande porte, pressupunha-se } \\
\text { que essa representatividade fosse maior. }\end{array}$ \\
\hline $\begin{array}{l}76 \% \text { dos respondentes da pesquisa trabalham, } \\
\text { direta ou indiretamente, na área de } \\
\text { Controladoria. }\end{array}$ & Perfil adequado para os objetivos da pesquisa. \\
\hline $\begin{array}{l}\text { 85\% das empresas elaboram o planejamento } \\
\text { estratégico de maneira formal. }\end{array}$ & $\begin{array}{l}\text { Demonstração de que essa técnica é comumente } \\
\text { utilizada, as demais empresas (15\%) indicaram a } \\
\text { existência de um processo de discussão sobre a } \\
\text { estratégia a ser adotada. }\end{array}$ \\
\hline 2) Participação da Controladoria no planejamento estratégico \\
\hline \multicolumn{2}{|l|}{$\begin{array}{l}\text { Efetuar a análise e a simulação do resultado global do } \\
\text { conjunto de estratégias definidas por área - maior } \\
\text { participação da Controladoria. }\end{array}$} \\
\hline $54 \%$ simulam alternativas de estratégia. & Concentração de informações de todas as áreas da \\
\hline
\end{tabular}




\begin{tabular}{|c|c|}
\hline informações. & organização. \\
\hline $\begin{array}{l}29 \% \text { possuem participação na formulação da } \\
\text { estratégia. }\end{array}$ & $\begin{array}{l}\text { Menor freqüência em virtude de os gestores de cada } \\
\text { atividade possuírem conhecimentos técnicos mais } \\
\text { adequados para formulação da estratégia. }\end{array}$ \\
\hline $\begin{array}{l}40 \% \text { participam da decisão sobre qual } \\
\text { estratégia deve ser adotada. }\end{array}$ & $\begin{array}{l}\text { Participação diferenciada do setor por possuir um } \\
\text { conhecimento mais profundo em relação aos } \\
\text { ambientes interno e externo à organização - ênfase } \\
\text { da participação do controllere da área. }\end{array}$ \\
\hline $\begin{array}{l}\text { 44\% coordenam a discussão dos cenários } \\
\text { econômicos. }\end{array}$ & $\begin{array}{l}\text { Participação mais sistêmica do controller - visão do } \\
\text { ambiente externo empresarial. }\end{array}$ \\
\hline $\begin{array}{l}75 \% \text { participam da consolidação dos } \\
\text { planejamentos de todas as áreas pela } \\
\text { Controladoria. }\end{array}$ & $\begin{array}{l}\text { Participação acentuada na consolidação do } \\
\text { planejamento. }\end{array}$ \\
\hline \multicolumn{2}{|c|}{ 3) Participação da Controladoria na elaboração, execução e controle do planejamento operacional. } \\
\hline $\begin{array}{l}67 \% \text { fazem a conversão da estratégia em } \\
\text { valores monetários realizada pela } \\
\text { Controladoria. }\end{array}$ & Área da Controladoria em desenvolvimento. \\
\hline $\begin{array}{l}81 \% \text { são responsáveis pelo monitoramento da } \\
\text { execução do planejamento operacional e } \\
\text { comunicação dos resultados obtidos. }\end{array}$ & $\begin{array}{l}\text { Confirma uma das principais funções da Controladoria: } \\
\text { o controle. }\end{array}$ \\
\hline \multicolumn{2}{|c|}{ 4) Participação da Controladoria na implantação e manutenção dos controles internos } \\
\hline $63 \%$ Controladoria como área responsável. & $\begin{array}{l}\text { Distribuição variada da responsabilidade, com ênfase } \\
\text { para a Controladoria. }\end{array}$ \\
\hline $\begin{array}{l}31 \% \text { são funções de todas as áreas da } \\
\text { organização. }\end{array}$ & $\begin{array}{l}\text { Inclusão da própria Controladoria. Utilização de } \\
\text { sistemas integrados de informações/características } \\
\text { específicas do modelo de gestão. }\end{array}$ \\
\hline $\begin{array}{l}65 \% \text { área responsável pela manutenção dos } \\
\text { controles internos. }\end{array}$ & $\begin{array}{l}\text { Confirmação da importância do setor no } \\
\text { monitoramento e manutenção do sistema de controles } \\
\text { internos, na qualidade das decisões tomadas. }\end{array}$ \\
\hline $\begin{array}{l}25 \% \text { é responsabilidade de todas as áreas na } \\
\text { manutenção dos controles internos. }\end{array}$ & $\begin{array}{l}\text { Provavelmente em razão do porte das organizações; } \\
\text { pela utilização de sistemas de acompanhamento. }\end{array}$ \\
\hline \multicolumn{2}{|c|}{ 5) A participação da Controladoria no monitoramento e manutenção do sistema de informações } \\
\hline $\begin{array}{l}52 \% \text { monitoramento e manutenção do sistema } \\
\text { de informações realizado pela Controladoria. }\end{array}$ & $\begin{array}{l}\text { A responsabilidade da Controladoria por essa função } \\
\text { não tão expressiva quanto enfatiza a teoria. }\end{array}$ \\
\hline $\begin{array}{l}\text { 21\% monitoramento e manutenção do sistema } \\
\text { de informações realizado pelo setor de } \\
\text { tecnologia da informação. }\end{array}$ & $\begin{array}{l}\text { Possível transferência dessa função pela influência da } \\
\text { estrutura e porte da organização. }\end{array}$ \\
\hline $\begin{array}{l}69 \% \text { a Controladoria é a área responsável pelo } \\
\text { fornecimento de informações gerenciais. }\end{array}$ & $\begin{array}{l}\text { Dados mais condizentes com as funções da área de } \\
\text { Controladoria em relação ao que é relatado pela } \\
\text { literatura. }\end{array}$ \\
\hline
\end{tabular}

\section{Quadro 1 - Participação da Controladoria no processo de gestão das organizações no Rio Grande do Sul}

Fonte: adaptado de Giongo (2005). 


\section{APRESENTAÇÃO E ANÁLISE DOS DADOS DA PESQUISA REALIZADA NO ESTADO DE SANTA CATARINA}

Na pesquisa realizada no Estado de Santa Catarina, especificamente na Região do Vale do Itajaí, foram investigadas as mesmas questões da pesquisa realizada por Giongo (2005), conforme explicitado na seção "método e procedimentos de pesquisa". Os resultados da pesquisa estão descritos no Quadro 2.

\begin{tabular}{|c|c|}
\hline DADOS & ANÁLISE \\
\hline \multicolumn{2}{|c|}{ 1) Análise do perfil das empresas e dos respondentes da pesquisa } \\
\hline $\begin{array}{l}\text { 89\% das empresas possuem área formalizada } \\
\text { de Controladoria. }\end{array}$ & $\begin{array}{l}\text { De um total de } 19 \text { empresas, apenas } 2 \text { não possuem } \\
\text { área de Controladoria formalizada. }\end{array}$ \\
\hline $\begin{array}{l}\text { 79\% dos respondentes da pesquisa trabalham, } \\
\text { direta ou indiretamente, na área de } \\
\text { Controladoria. }\end{array}$ & Perfil adequado aos objetivos da pesquisa. \\
\hline $\begin{array}{l}84 \% \text { das empresas elaboram o planejamento } \\
\text { estratégico de maneira formal. }\end{array}$ & $\begin{array}{l}\text { A técnica é comumente utilizada, pois as demais } \\
\text { empresas }(16 \%) \text { indicaram a existência de um processo } \\
\text { de discussão sobre a estratégia a ser adotada. }\end{array}$ \\
\hline \multicolumn{2}{|c|}{ 2) Participação da Controladoria no planejamento estratégico } \\
\hline $\begin{array}{l}\text { 68\% efetuam simulação das alternativas de } \\
\text { estratégia. }\end{array}$ & $\begin{array}{l}\text { Efetuar a análise e a simulação do resultado global do } \\
\text { conjunto de estratégias definidas por área. }\end{array}$ \\
\hline $\begin{array}{l}52 \% \text { encarregam-se do fornecimento de } \\
\text { informações. }\end{array}$ & Concentração de informações de todas as áreas. \\
\hline $\begin{array}{l}58 \% \text { há participação na formulação da } \\
\text { estratégia. }\end{array}$ & $\begin{array}{l}\text { Menor freqüência em virtude dos gestores de cada } \\
\text { atividade possuírem conhecimento técnico mais } \\
\text { adequado para formulação da estratégia. }\end{array}$ \\
\hline $\begin{array}{l}52 \% \text { participam da decisão sobre qual } \\
\text { estratégia deve ser adotada. }\end{array}$ & $\begin{array}{l}\text { Participação diferenciada do setor por possuir um } \\
\text { conhecimento mais profundo em relação aos ambientes } \\
\text { interno e externo da organização. }\end{array}$ \\
\hline $\begin{array}{l}\text { 47\% participam da discussão dos cenários } \\
\text { econômicos. }\end{array}$ & $\begin{array}{l}\text { Participação mais sistêmica do controller - visão do } \\
\text { ambiente externo empresarial. }\end{array}$ \\
\hline $\begin{array}{l}74 \% \text { respondem pela consolidação dos } \\
\text { planejamentos de todas as áreas pela } \\
\text { Controladoria. }\end{array}$ & $\begin{array}{l}\text { Participação acentuada na consolidação do } \\
\text { planejamento. }\end{array}$ \\
\hline \multicolumn{2}{|c|}{ 3) Participação da Controladoria na elaboração, execução e controle do planejamento operacional. } \\
\hline $\begin{array}{l}\text { 74\% fazem a conversão da estratégia em } \\
\text { valores monetários realizada pela Controladoria. }\end{array}$ & Área da Controladoria em desenvolvimento. \\
\hline $\begin{array}{l}68 \% \text { Controladoria é responsável pelo } \\
\text { monitoramento da execução do planejamento } \\
\text { operacional e comunicação dos resultados } \\
\text { obtidos. }\end{array}$ & $\begin{array}{l}\text { Confirma uma das principais funções da Controladoria: } \\
\text { o controle. }\end{array}$ \\
\hline \multicolumn{2}{|c|}{ 4) Participação da Controladoria na implantação e manutenção dos controles internos } \\
\hline $\begin{array}{l}68 \% \text { têm a Controladoria como área } \\
\text { responsável. }\end{array}$ & $\begin{array}{l}\text { Distribuição variada da responsabilidade, com ênfase } \\
\text { para a Controladoria. }\end{array}$ \\
\hline $21 \%$ são funções de todas as áreas da & Inclusão da própria Controladoria. Utilização de \\
\hline
\end{tabular}




\begin{tabular}{|l|l|}
\hline organização. & $\begin{array}{l}\text { sistemas integrados de informações/características } \\
\text { específicas do modelo de gestão. }\end{array}$ \\
\hline $\begin{array}{l}74 \% \text { a área é responsável pela manutenção dos } \\
\text { controles internos. }\end{array}$ & $\begin{array}{l}\text { Confirmação da importância do setor no monitoramento } \\
\text { e manutenção do sistema de controles internos, na } \\
\text { qualidade das decisões tomadas. }\end{array}$ \\
\hline $\begin{array}{l}16 \% \text { é responsabilidade de todas as áreas na } \\
\text { manutenção dos controles internos. }\end{array}$ & $\begin{array}{l}\text { Provavelmente em razão do porte das organizações; } \\
\text { pela utilização de sistemas de acompanhamento. }\end{array}$ \\
\hline 5$)$ Participação da Controladoria no monitoramento e manutenção do sistema de informações \\
\hline $\begin{array}{l}74 \% \text { monitoramento e manutenção do sistema } \\
\text { de informações realizado pela Controladoria. }\end{array}$ & $\begin{array}{l}\text { A responsabilidade da Controladoria por essa função } \\
\text { não tão expressiva quanto enfatiza a teoria. }\end{array}$ \\
\hline $\begin{array}{l}11 \% \text { monitoramento e manutenção do sistema } \\
\text { de informações realizado pelo setor de Tl. }\end{array}$ & $\begin{array}{l}\text { Possível transferência dessa função pela influência da } \\
\text { estrutura e porte da organização. }\end{array}$ \\
\hline $\begin{array}{l}79 \% \text { têm a Controladoria como área } \\
\text { responsável pelo fornecimento de informações } \\
\text { gerenciais. }\end{array}$ & $\begin{array}{l}\text { Dados mais condizentes com as funções da área de } \\
\text { Controladoria em relação ao que é relatado pela } \\
\text { literatura. }\end{array}$ \\
\hline
\end{tabular}

\section{Quadro 2 - Participação da Controladoria no processo de gestão das organizações em Santa Catarina}

Fonte: dados da pesquisa.

\section{COMPARAÇÃO DOS RESULTADOS DAS PESQUISAS REALIZADAS NOS ESTADOS DO RIO GRANDE DO SUL E DE SANTA CATARINA}

A partir dos dados coletados, foi possível traçar um comparativo que permite uma análise dos fatores convergentes e divergentes no que tange à participação da Controladoria no processo de gestão das organizações nos dois Estados. A Tabela 1 apresenta os dados comparativos.

Tabela 1 - Comparação dos resultados das pesquisas realizadas nos Estados do RS e SC

\begin{tabular}{lccc}
\hline \multicolumn{1}{c}{ DADOS DA PESQUISA } & \%RS & $\%$ SC \\
\hline 1) Perfil das empresas e dos respondentes da pesquisa & & \\
\hline Empresas que possuem área formalizada de Controladoria. & 73 & 89 \\
Respondentes da pesquisa que trabalham, direta ou indiretamente, na área de & 76 & 79 \\
Controladoria. & 85 & 84 \\
Empresas que elaboram o planejamento estratégico de maneira formal. & & \\
\hline 2) Participação da Controladoria no planejamento estratégico & 56 & 68 \\
\hline Simulação das alternativas de estratégia. & 54 & 52 \\
Fornecimento de informações. & 29 & 58 \\
Participação na formulação da estratégia. & 40 & 52 \\
Decisão sobre qual estratégia deve ser adotada. & 44 & 47 \\
Discussão dos cenários econômicos. & 75 & 74 \\
Consolidação dos planejamentos de todas as áreas pela Controladoria. & & \\
\hline
\end{tabular}




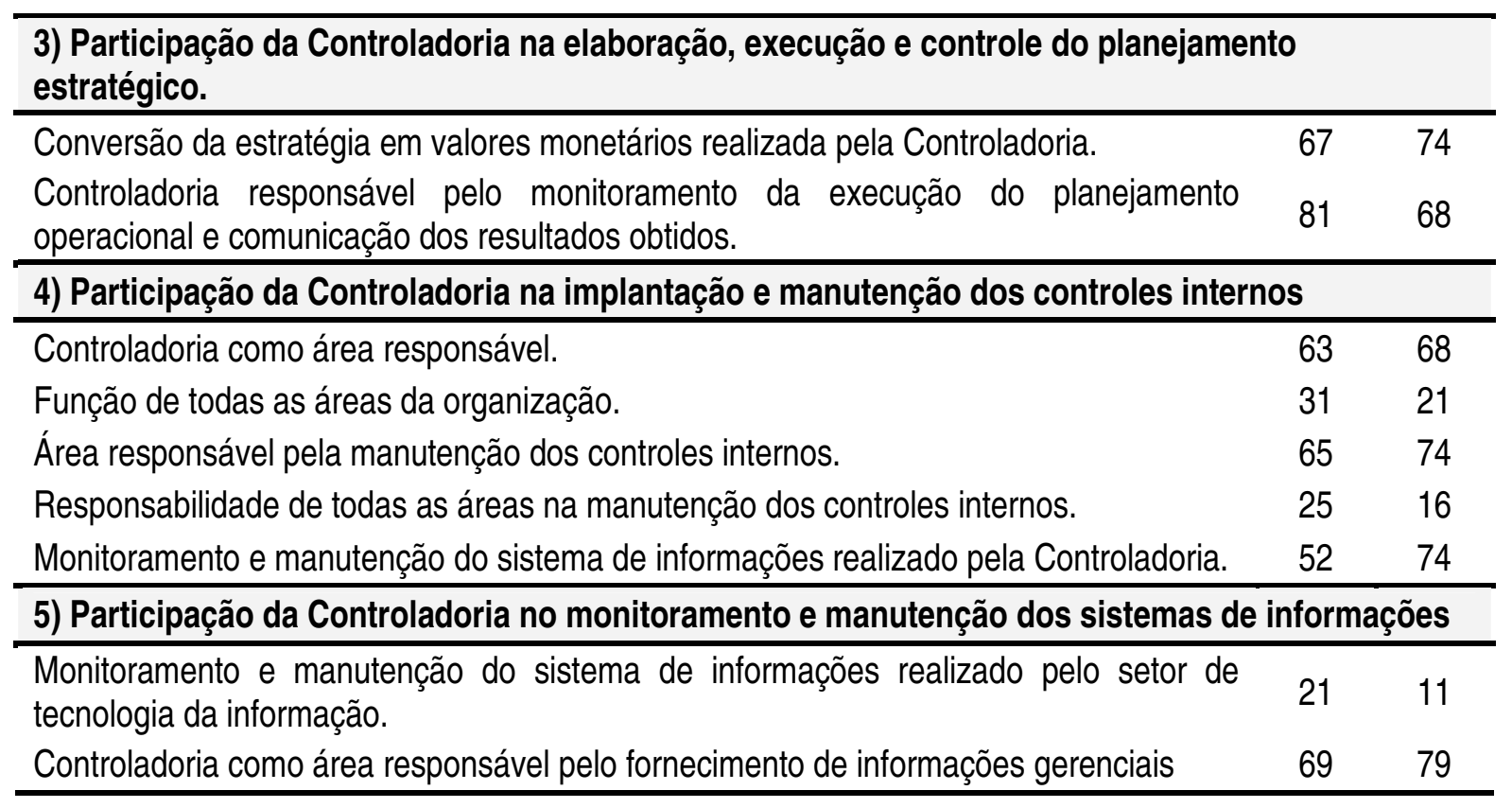

Fonte: dados da pesquisa.

As principais semelhanças identificadas entre os dois Estados, a partir da análise da Tabela 1, são as seguintes:

a) na análise do perfil das empresas e dos respondentes da pesquisa: a maioria das empresas elaboram o planejamento estratégico de maneira formal e os respondentes da pesquisa trabalham, direta ou indiretamente, na área de Controladoria;

b) sobre a participação da Controladoria no planejamento estratégico: é razoável a participação através do fornecimento de informações, baixa na discussão dos cenários econômicos e boa na consolidação dos planejamentos de todas as áreas.

Por outro lado, as principais diferenças identificadas nas pesquisas em empresas gaúchas e catarinenses, são as seguintes:

a) na análise do perfil das empresas e dos respondentes: na pesquisa em SC o percentual de empresas que possuem área formalizada de Controladoria é $22 \%$ maior;

b) sobre a participação da Controladoria no planejamento estratégico: na simulação das alternativas de estratégia, o percentual de SC supera em 21\% o do RS; a participação na formulação da estratégia em SC é $100 \%$ maior que no RS e na decisão sobre qual estratégia deve ser adotada, o percentual de SC supera o do RS em $30 \%$;

c) na participação da Controladoria na elaboração, execução e controle do planejamento estratégico: em SC, a conversão da estratégia em valores monetários realizada pela Controladoria é $10 \%$ maior que no outro Estado; o setor como responsável pelo monitoramento da execução do planejamento operacional e comunicação dos resultados obtidos é maior em $19 \%$ no RS;

d) a participação da Controladoria na implantação e manutenção dos controles internos: a Controladoria como área responsável é superior em $8 \%$ em SC; como função de todas as 
áreas da organização, é $48 \%$ maior no RS que em SC; como área responsável pela manutenção dos controles internos é superior em 14\% em SC; a responsabilidade de todas as áreas na manutenção dos controles internos é $56 \%$ maior no RS; o monitoramento e manutenção do sistema de informações realizado pela Controladoria é superior em $42 \%$ em SC.

e) a participação da Controladoria no monitoramento e manutenção dos sistemas de informações: no monitoramento e manutenção do sistema de informações realizado pelo setor de tecnologia da informação é $91 \%$ maior no RS; a Controladoria como área responsável pelo fornecimento de informações gerenciais é superior em SC em 14\%.

A Tabela 2 apresenta a média dos fatores pesquisados em relação às atividades exercidas pela Controladoria nos Estados do Rio Grande do Sul e Santa Catarina.

\section{Tabela 2 - Média dos fatores pesquisados das atividades exercidas pela Controladoria nos Estados de RS e SC}

\begin{tabular}{lcc}
\hline \multicolumn{1}{c}{ DESCRIÇÃO DAS ATIVIDADES DA CONTROLADORIA } & $\begin{array}{c}\text { MÉDIA \% } \\
\text { RS }\end{array}$ & $\begin{array}{c}\text { MEDIA } \% \\
\text { SC }\end{array}$ \\
\hline Análise do perfil das empresas e dos respondentes da pesquisa & $78 \%$ & $84 \%$ \\
A participação da Controladoria no planejamento estratégico & $50 \%$ & $58 \%$ \\
$\begin{array}{l}\text { A participação da Controladoria na elaboração, execução e controle do } \\
\text { planejamento estratégico. }\end{array}$ & $74 \%$ & $71 \%$ \\
$\begin{array}{l}\text { A participação da Controladoria na implantação e manutenção dos } \\
\text { controles internos }\end{array}$ & $46 \%$ & $45 \%$ \\
$\begin{array}{l}\text { A participação da Controladoria no monitoramento e manutenção do } \\
\text { sistema de informações }\end{array}$ & $47 \%$ & $55 \%$ \\
\hline
\end{tabular}

Fonte: dados da pesquisa.

Pela análise de dados, foi possível identificar de fatores semelhantes no que tange à participação da Controladoria no processo de gestão empresarial entre os dois Estados. Porém, cabe ressaltar que, das 19 empresas pesquisadas em Santa Catarina, somente 5\% são de capital estrangeiro, ao passo que, das 48 pesquisadas no Rio Grande Sul, 15 empresas, 31\% são de capital externo. Isso leva à reflexão de que as empresas nacionais estão preocupadas com sua gestão e estão cada vez mais se utilizando de controles para aumentar sua eficiência e eficácia.

\section{CONCLUSÕES}

O objetivo deste estudo foi traçar um comparativo entre a participação da Controladoria no processo de gestão em grandes indústrias de Santa Catarina e do Rio Grande do Sul. Foram utilizados dados da pesquisa realizada por Giongo (2005) em 48 grandes indústrias do Rio Grande do Sul e reaplicado o mesmo questionário em 20 grandes indústrias têxteis de Santa Catarina.

A comparação entre resultados das duas pesquisas demonstra que as principais semelhanças estão: no perfil das empresas e dos responsáveis pelo setor; na participação do setor na elaboração, 
execução e controle do planejamento estratégico e na implantação e manutenção dos controles internos. As principais divergências verificadas dizem respeito à participação da Controladoria no planejamento estratégico e no monitoramento e manutenção do sistema de informações.

Como pontos fortes da participação da Controladoria no processo de gestão das organizações do Estado de Santa Catarina, pode-se citar: área formalizada de Controladoria; participação no planejamento; simulação das alternativas de estratégia; decisão sobre qual estratégia deve ser adotada; a conversão da estratégia em valores monetários realizada pelo setor; a Controladoria como área responsável pela implantação e manutenção dos controles internos; o monitoramento e manutenção do sistema de informações realizado pela Controladoria; a Controladoria como área responsável pelo fornecimento de informações gerenciais.

Na pesquisa realizada no Estado do Rio Grande do Sul, pode-se destacar como pontos fortes: o setor como responsável pelo monitoramento da execução do planejamento operacional e comunicação dos resultados obtidos; a participação da Controladoria na implantação e manutenção dos controles internos como função de todas as áreas da organização e 0 monitoramento e manutenção do sistema de informações realizado pelo setor de tecnologia.

O trabalho permitiu, também, uma análise comparativa entre a Controladoria preconizada pela teoria e o papel que ela assume na prática, sua aplicabilidade e objetividade. Este estudo limitou-se à população selecionada, sendo relevante a ampliação da pesquisa para outros Estados, bem como a investigação de quais fatores influenciam no processo de participação da Controladoria na gestão das organizações, visto que, a partir da pesquisa realizada nos dois Estados, várias diferenças foram evidenciadas.

\section{REFERÊNCIAS}

ALMEIDA, Lauro Brito de; PARISI, Cláudio; PEREIRA, Carlos Alberto. Controladoria. In: CATELLI, Armando. (Coord.). Controladoria: uma abordagem da gestão econômica - GECON. 2. ed. São Paulo: Atlas, 2001.

ANDREATTA, Adalberto. A Controladoria nas grandes indústrias têxteis do Vale do Itajaí/SC. 2005. 150 f. Dissertação (Mestrado em Ciências Contábeis) - Curso de Pós-Graduação em Ciências Contábeis, Universidade Regional de Blumenau, Blumenau, 2005.

ANTHONY, Robert Newton; GOVINDARAJAN, Vijay. Sistemas de controle gerencial. São Paulo: Atlas, 2002.

BEUREN, Ilse Maria. O papel da Controladoria no processo de gestão. In: SCHIMIDT, Paulo (Org.). Controladoria: agregando valor para a empresa. Porto Alegre: Bookmann, 2002. p. 15-38.

COLAUTO, Romualdo Douglas; BEUREN, Ilse Maria. Coleta, análise e interpretação dos dados. In: BEUREN, Ilse Maria (Org.). Como elaborar trabalhos monográficos: teoria e prática. São Paulo: Atlas, 2004. p. 117-144.

FIGUEIREDO, Sandra; CAGIANO, Paulo César. Controladoria: teoria e prática. 3. ed. São Paulo: Atlas, 2004.

GIL, Antonio Carlos. Métodos de pesquisa social. 5. ed. São Paulo: Atlas, 1999. 
GIONGO, Juliano. A participação da Controladoria no processo de gestão organizacional. 2005. 137 f. Dissertação (Mestrado em Ciências Contábeis) - Curso de Pós-Graduação em Ciências Contábeis, Universidade do Vale do Rio dos Sinos, São Leopoldo, 2005.

KANITZ, Stefen Charles. Controladoria: teoria e estudos de casos. São Paulo, Pioneira, 1976.

MARTINS, Gilberto de Andrade. Manual para elaboração de monografias e dissertações. São Paulo. 3 ed. São Paulo: Atlas, 2002.

MOSIMANN, Clara Pelegrinello; FISCH, Silvio. Controladoria: seu papel na administração de empresas, 2. ed. São Paulo, Atlas, 1999.

OLIVEIRA, Luis Martins de. Controladoria: conceitos e aplicações. São Paulo: Futura, 1998.

PELEIAS, Ivam Ricardo. Controladoria: gestão eficaz utilizando padrões. São Paulo: Saraiva, 2002.

PEREZ JUNIOR, José Hernandes; PESTANA, Armando Oliveira; FRANCO, Sergio Paulo Cintra.

Controladoria de gestão: teoria e pratica. São Paulo: Atlas, 1997.

PEREZ JUNIOR, José Hernandes; OLIVIERA, Luis Martins de; COSTA, Rogério Guedes. Gestão estratégica de custos. São Paulo: Atlas, 1999.

RAUPP, Fabiano Maury; BEUREN, Ilse Maria. Metodologia da pesquisa aplicável às ciências sociais. In: BEUREN, Ilse Maria (Org.). Como elaborar trabalhos monográficos: teoria e prática. São Paulo: Atlas, 2004. p. 76-97.

RICCIO, Edson Luiz; PETERS, Marcos R. S. Novos paradigmas para a função Controladoria. In: ENCONTRO NACIONAL DOS PROGRAMAS DE PÓS-GRADUAÇÃO EM ADMINISTRAÇÃO, 17, 1993, Salvador/BA. Anais... Rio de Janeiro, ANPAD, 1993.

RICHARDSON, Roberto Jarry. Metodologia da pesquisa em ciências sociais: um tratamento conceitual. São Paulo: EPU, 1980.

\title{
THE PARTICIPATION OF CONTROLLERSHIP IN THE PROCESS OF MANAGING ORGANIZATIONS: A COMPARATIVE ANALYSIS BETWEEN LARGE INDUSTRIES OF SANTA CATARINA AND RIO GRANDE DO SUL
}

\begin{abstract}
Knowing the role of the Controller and its functions is the first step in implanting a Controllership department in a company, but it is also important to make managers conscious of the need to work together in order to make the enterprise viable. The objective of this article is to present a comparative of the participation of controllership in the process of managing large industries in the states of Santa Catarina and Rio Grande Sul. As a basis for comparison, a questionnaire that was originally utilized in the dissertation of Juliano Giongo (2005) was reused. The questionnaire surveyed large industries from Rio Grande do Sul and 20 textile companies from the Vale do Itajaí in Santa Catarina. The research results show the performance of controllership in companies from different regions and states, showing different methods of management. This work presents information from the industries in relation to the growth of controllership and from the persons responsible for that control, analyzing its applicability and objectivity. From the analysis, similar and divergent factors were found with regard to the participation of financial control in the process of company management between the two states researched.
\end{abstract}

Key words: Controllership. Process of company management. Companies from Rio Grande do Sul and Santa Catarina. 